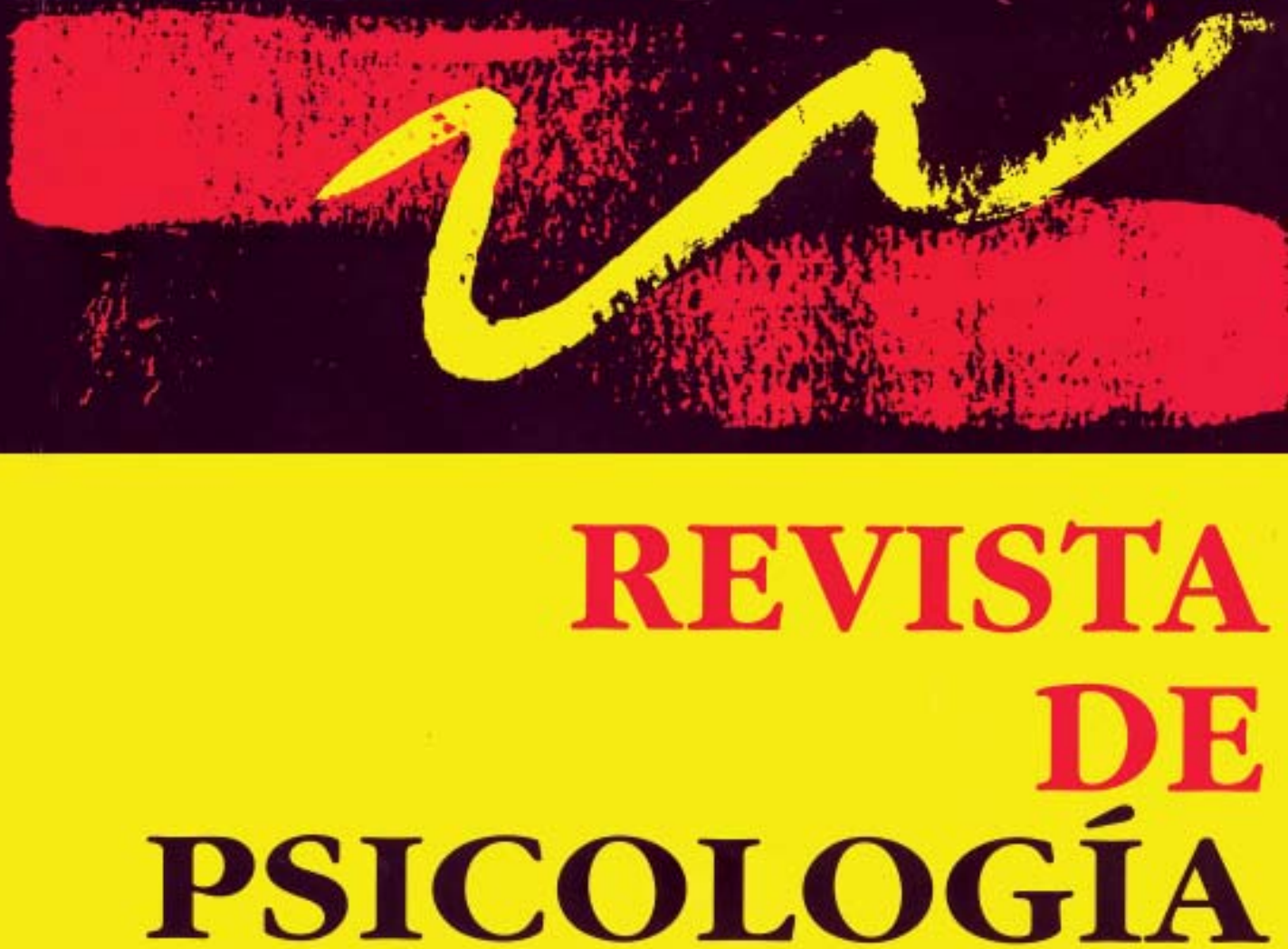

Silencio como secuela de la guerra interna en Perú

Comportamiento antisocial en menores escolares

e indigentes: influencia del vecindario y de los padres

La unidimensionalidad de un instrumento de medición: perspectiva factorial

Calidad de la amistad en niños de 8 a 10 años de una institución pública

Afrontamiento a la enfermedad crónica:

estudio en pacientes con insuficiencia renal crónica terminal
Javier Iguíñiz Echeverría

Ana Lilia Banda Castro y Martha Frías Armenta

Andrés Burga León

Doris Argumedo Bustinza y Carla Albornoz Álvarez

Mónica Cassaretto y Rosario Paredes

Reseña 


\section{REVISTA DE PSICOLOGÍA}

\section{Vol. XXIV. Primer semestre 2006 N $^{\circ} 1$ \\ CONTENIDO}

\section{ARTÍCULOS}

Javier Iguíniz Echeverría. Silencio como secuela de la guerra interna en Perú.

Ana Lilia Banda Castro y Martha Frías Armenta. Comportamiento antisocial en menores escolares e indigentes: influencia del vecindario y de los padres.

Andrés Burga León. La unidimensionalidad de un instrumento de medición: perspectiva factorial.

Doris Argumedo Bustinza y Carla Albornoz Álvarez. Calidad de la amistad en niños de 8 a 10 años de una institución pública.

Mónica Cassaretto y Rosario Paredes. Afrontamiento a la enfermedad crónica: estudio en pacientes con insuficiencia renal crónica terminal.

RESEÑA 
Revista de Psicología de la PUCP. Vol. XXIV, 1, 2006

\title{
Silencio como secuela de la guerra interna en Perú 1
}

\author{
Javier Ma . Iguíñiz Echeverría² \\ Pontificia Universidad Católica del Perú
}

\begin{abstract}
La guerra interna durante más de dos lustros en el Perú ha tenido como una de sus secuelas el silencio. En este artículo proponemos una clasificación de silencios o de aspectos del silencio. La clasificación, basada en un ordenamiento de las experiencias relatadas en el Informe de la Comisión de la Verdad y Reconciliación (CVR, 2003), consiste en distinguir un silencio instrumental o silencio para; un silencio producto de lo terrible de los hechos ocurridos, silencio de; uno producto de la ausencia de interlocutores importantes para la comunicación más íntima, como familiares o amigos, silencio con; y finalmente, un silencio más profundo, menos descriptible, más personal pero menos manejable, silencio a secas.

Palabras clave: guerra, silencio, Comisión de la Verdad y Reconciliación.
\end{abstract}

\section{Silence as a sequel of the Peruvian internal war}

The internal war that took place in Peru for two decades brought silence as one of its consequences. In this article we try to classify silence or aspects of silence. This classification, based on the experiences described in the Report of the Truth and Reconciliation Commission (CVR, 2003), distinguishes an instrumental silence or silence for; a silence caused by the terrible events that took place or silence from; a silence resulting from the absence of important relations for an intimate communication, like relatives or friends, or silence with; and finally, a more profound silence, less describable, more personal but less manageable, simply a silence.

Keywords: war, silence, Truth and Reconciliation Commission.

1 Este artículo es una versión en castellano con ínfimas modificaciones de la ponencia presentada en el Cuarto Congreso Internacional del Human Development and Capability Association (HDCA) Enhancing Human Security, que tuvo lugar en Pavia, Italia entre el 5 y el 7 de septiembre del 2004. Agradezco las lecturas de versiones previas y los consejos para su elaboración de Fryné Santistevan, Aquilino Gonzáles. También el apoyo para la versión original de Walter Blake y Jan-David Gelles, así como para esta versión de María Catalina Iguíñiz, Javier Mello y Pavel Coronado. Los cuidados de edición han corrido a cargo de Beatriz Gonzáles. La responsabilidad final es totalmente del autor.

2 Profesor Principal y Jefe del Departamento de Economía de la PUCP. Correo electrónico: jiguini@pucp.edu.pe 

Muchas secuelas de cualquier guerra son factores de reducción del desarrollo de las personas, tanto en el corto como en el largo plazo. El sufrimiento y el temor generalmente reducen el desarrollo humano ${ }^{3}$. El silencio individual emergente de experiencias traumáticas de dolor y violencia es una manifestación de falta de libertad y su efecto puede multiplicarse en la sociedad. La libertad de expresarse, particularmente de expresar los sentimientos más íntimos, está en los fundamentos de muchas otras libertades. En este artículo queremos resumir algunas de las consecuencias de la guerra interna que en el Perú se desarrolló desde 1980 hasta 1992 y presentar en cierto detalle una de ellas: la dificultad para comunicar la experiencia de terror y humillación sufrida por cientos de miles de individuos y comunidades.

\section{Un pequeño resumen de la guerra interna}

El 18 de mayo de 1980, luego de más de once años de dictadura militar, el Perú tuvo elecciones generales. Ese mismo día fue el momento escogido por el Partido Comunista del Perú («Sendero Luminoso») para dar una orientación maoísta para comenzar la guerra. Ellos destruyeron las ánforas en un pueblo extremadamente pequeño arriba en los Andes. Esta ubicación inicial es representativa de una de las características del conflicto: fue mayormente en esas partes del país que ocurrió y, por ello, no fue de interés para las elites y para muchos ciudadanos en las grandes ciudades y en las regiones relativamente más desarrolladas de la costa del país. Para muchos fue una guerra en algún «otro» país. En este sentido, fue durante un buen tiempo una guerra silenciosa. 
En medio de muchas características interesantes de la guerra, tal vez el aspecto más importante para nuestro propósito aquí es que eso estuvo diseñado a propósito para concentrar lo peor de la guerra en la población civil. Avances subversivos iniciales en un territorio débilmente controlado y la indiscriminada reacción de las Fuerzas Armadas Peruanas (FFAA) llevaron a una terrible contrareacción de Sendero Luminoso (SL) en contra de una población que no estaba plenamente convencida del mensaje comunista y estaba siempre en peligro de perderse para la causa revolucionaria.

Siguiendo una bien conocida estrategia de guerrilla rural maoísta, Sendero Luminoso mató muchas autoridades de pueblos pequeños, dueños de tiendas, dueños de tierras y campesinos, muchos de ellos corruptos o abusivos, pero también democráticamente electos, y crearon en un muy corto tiempo lo que demostró ser un «nuevo poder» social y político bastante artificial y débil. En cualquier caso, todo ello concluyó tras el inicio de una brutal reacción de las fuerzas de seguridad que atacaron tan fácil como masivamente la población para matar las nuevas autoridades y a todos aquellos que las protegían o eran sospechosos de protegerlas. Eso no era, sin embargo, una guerra entre gente armada enfrentándose abierta o de manera sorpresiva sino que cada uno operó atacando mayormente población civil. La mayoría de los episodios masivos de violencia militar y terror fueron en contra de las personas no armadas. Que esto fue planeado por SL es absolutamente claro; fue también parte del discurso oficial a los militantes por Guzmán, su líder.

El prestigio social de gente andina, joven y educada fue un elemento central en la iniciación de la guerra. La educación era la herramienta básica para la promoción social y la diferenciación social en los Andes peruanos y llegó a ser importante

4 Expresiones como «cruzar el río de sangre», «un millón de muertos serán necesarios», «tener la vida en la yema de los dedos», y muchas otras similares fueron muy comunes. 
porque la mayoría de los militantes iniciales de SL eran profesores relativamente bien educados y estudiantes universitarios, quienes retornaron a sus pequeñas localidades para crear el «vacío de poder»y para instalar un «nuevo poder» ${ }^{5}$. Mas generalmente, los conflictos locales y los abusos de poder en las áreas rurales, la negligencia del Estado y el prestigio de la juventud educada recientemente retornada fueron algunos de los ingredientes claves a la hora de explicar el levantamiento de la población en contra de los relativamente ricos pero en muchos casos pobres en términos absolutos, dueños de tierras y autoridades locales en los miserables Andes peruanos ${ }^{6}$. Pero un «Nuevo Estado» y nuevas relaciones sociales no pueden ser creadas en un territorio que ya había experimentado una masiva salida de los principales dueños de tierra y después de eso una reforma agraria radical en la década previa. La estructura de la tierra estaba caracterizada por pequeñas parcelas, principalmente compuestas por minifundios. Una vez que algunas pequeñas redistribuciones de bienes y ganado tuvieron lugar tras la asunción del control por SL, la vida siguió como era normal con la dificultad añadida proveniente de las restricciones impuestas por SL para comerciar. Además, geográficamente hablando, no había lugar densamente poblado que pudiera estar aislado militarmente; no había lugar para esconderse en una región donde hay muy pocos árboles ${ }^{7}$. El resultado fue una competencia de crueldad en contra de la población local que, al final, tomó partido por las Fuerzas Armadas que pudieron permanecer cerca más establemente para defenderlos en contra de la permanente movilización de SL. Las consecuencias de una guerra dependen del tipo de conflicto y éste era particularmente letal para los ciudadanos ${ }^{8}$.

5 El sumario de las características de la guerra se puede encontrar en el Vol. I del Informe de la Comisión de la Verdad y Reconciliación del Perú. La cuenta detallada en los Vols. II-VII.

6 Muchas provincias en los Andes tuvieron tasas de mortalidad infantil similares al promedio de los países subsaharianos.

$7 \quad$ Era más poblado y comunicado que la China que inspiró a Guzmán (VIII 48).

8 Se considera que en la Latinoamérica contemporánea sólo el conflicto de Guatemala fue más terrible en contra de la población indígena. 
En la historia peruana, los conflictos de largo plazo han sido raros y las secuelas también dependen de la duración. ¿Por qué duró tanto esta guerra? ${ }^{9}$ Primero, fue una completa sorpresa y no fue tomada seriamente por varios gobiernos. Otro factor fue que SL no dependió de ningún poder externo como fuente de abastecimiento. Tercero, la base social de militantes estaba ideológicamente bien preparada y muchos de ellos radicalizaron a los miembros de otros partidos izquierdistas que tenían una callada pero extendida presencia en todo el territorio peruano y particularmente en las ciudades provincianas. Cuarto, el Estado replicó con gran crueldad, como SL quiso y planeó que lo hiciera, «confirmando» el análisis producido por Guzmán acerca de la naturaleza moral de la estructura del poder en el Perú y dando poder ideológico a los militantes. La «crisis de deuda» peruana durante los años 80, la más prolongada y quizás la más profunda en América Latina, también fue un factor. Una sociedad urbana concentrada en el esfuerzo de reaccionar a una extremadamente profunda crisis económica no estaba interesada en lo que estaba ocurriendo en los Andes. El racismo tradicional contribuyó a la falta de interés y a la ausencia de políticas democráticamente deliberadas en contra de los rebeldes.

\section{Muchas secuelas ${ }^{10}$}

Un conflicto de tales características tuvo muchos efectos. Vamos a utilizar la definición de secuelas presentada por la CVR que entiende secuelas como «el conjunto de efectos perjudiciales sobre la vida y la comunidad producidos por las acciones de violencia,

Es una pregunta hecha por el reporte. Tomamos algunos de los factores presentados allí (VIII 40-46).

10 Hemos aprendido que diferentes escuelas en el mundo de los psicólogos frasearían algunas, si no muchas, de nuestras oraciones de una manera diferente y más técnica. Algunos también descartarían varios elementos. Pero, de todos modos, esperamos que nuestra propuesta clasificatoria sea útil para sugerir acciones que enfrenten y traten de atenuar el problema bajo estudio. 
en la medida en que éstas han destruido, desarticulado o dañado, de modo temporal o permanente las condiciones estructurales, físicas, sociales y psicológicas de la vida colectiva, al igual que la integridad personal de sus miembros ${ }^{11}$.

La CVR investigó con bastante detalle las secuelas psico-sociales, socio-políticas y socio-económicas. La complejidad del análisis de las secuelas es grande por varias razones, entre ellas, la dificultad de capturar los diversos aspectos y las profundidades de cada una ellas. A esa dificultad se añade el hecho de que hay interrelaciones entre ellas y que es necesario detectar el fin o la mutación en el tiempo de los efectos inmediatos y originales. Finalmente, los múltiples efectos sociales de las consecuencias directas e inmediatas no son fáciles de detectar en el análisis.

Algunas de las primeras de esas secuelas, específicamente las de silencio, serán analizadas o, por lo menos, ordenadas en cierto detalle en la siguiente sección. Entre aquellas a un nivel principalmente individual podemos distinguir aquí: a) el miedo que resurge cada vez que se renueva la sensación de que un nuevo levantamiento es aun posible; b) la desconfianza y el aislamiento que sigue al debilitamiento de los vínculos sociales en el nivel comunal y familiar; c) el abandono y el desamparo que determina a veces la frustración y la falta de esperanza; d) la confusión que dificulta o impide explicaciones, y prolonga la dificultad de darle sentido a la experiencia; e) los sentimientos de culpa resultantes de muchas decisiones que son percibidas como costosas en términos de sufrimiento para los demás; f) la negación al tratar de no

11 (VIII 183) Para este reporte y el análisis de las consecuencias psicológicas se tomó en cuenta, entre otras, las siguientes fuentes: «testimonios recopilados, historias grabadas por los entrevistadores, grupos focales, talleres que forman parte de la base de datos de los estudios a profundidad, los propios hallazgos de la CVR y los informes de las sedes regionales».(VIII 183). También se tomaron en cuenta otras actividades que la CVR utilizó para reunir información adicional como los comentarios públicos, exhumaciones, documentos de trabajo que fueron comisionados para investigar el problema. 
saber qué pasó; g) la tristeza derivada en vaciedad y en falta de energía para participar en la vida social; h) las humillaciones impuestas que vienen de siglos de viejas humillaciones y la pérdida del sentido de la dignidad; i) la humillación y el resentimiento, ambos peligrosos para aquellos que viven con los que los sufren; h) las enfermedades que reflejan sufrimientos íntimos; i) la pérdida de objetivos muy queridos en la vida y las sensaciones consiguientes están también en medio de las muchas secuelas que han sido presentadas tan abierta y francamente como fue posible a la CVR en el Perú ${ }^{12}$. Todo esto ha producido, en diferentes combinaciones, un profundo impacto en cientos de miles de vidas.

En el nivel familiar, encontramos muchas secuelas sociales que tienen consecuencias psicológicas que también son comunes a muchas guerras. En medio de ellas, la fragmentación, la violencia, la orfandad, la pérdida de un miembro de la pareja casada, otros miembros de la familia desaparecidos, la ausencia del duelo, las prolongadas estancias en la cárcel, han sido mencionadas muchas veces en las entrevistas.

Las secuelas socio-políticas se concentran en la estructura del gobierno a nivel local y comunal, y las principales consecuencias son divididas por el reporte en tres componentes. En el nivel comunal, el desalojo y la reubicación de la población han sido muy importantes debido al debilitamiento de los vínculos entre la población y la tierra. A las antiguas razones para migrar, la guerra añadió motivos muy fuertes para abandonar los pueblos. El reporte destaca un segundo efecto: la falta de de normas y el incremento diario de violencia a nivel local. La ruptura de las normas sociales existentes y la ausencia de nuevas que las reemplacen, llevaron a la expansión de delincuencia y formación pandillera en las ciudades más afectadas por la guerra. En tercer lugar, la guerra exacerbó 
los tradicionales y, muchas veces, sutiles conflictos entre las comunidades y también entre familias y entre vecindarios, muchas veces por pequeñas parcelas de tierra. La acción inicial en contra del poder local por SL y la arbitrariedad de las FFAA en el nombramiento de nuevas autoridades en el territorio dominado por ellos permitió el reclamo airado de antiguas demandas, y también el surgimiento de la violencia entre pueblos y entre vecindarios. La organización de los grupos de defensa propia por las FFAA contribuyó al retiro de SL pero también a muchas atrocidades cometidas por tales grupos y a una extendida impunidad.

El asesinato de autoridades políticas fue masivo en las regiones donde había una concentración de la guerra. Aproximadamente 2,267 autoridades y líderes sociales fueron asesinados o desaparecidos ${ }^{13}$. Muchos nuevos fueron instalados por las FFAA en contra de su voluntad. La participación social local en la esfera política fue también destruida por la aproximación militar tanto de SL como de las FFAA.

Las secuelas socio-económicas incluidas en el reporte están relacionadas al impacto en el «capital humano», tierras de agricultura, ganado y otros bienes, y también a la base institucional de la actividad productiva ${ }^{14}$. El capital humano en las regiones ha sido seriamente afectado por el desplazamiento y el proceso migratorio. La mayoría de las víctimas (muertos y desaparecidos) fueron hombres entre 18 y 34 años de edad. Los desplazamientos masivos también redujeron la población en las provincias más afectadas. A pesar de las altas tasas de natalidad, la Población Económicamente Activa en todo el departamento de Ayacucho se redujo de $154 \mathrm{mil}$ en 1981 a 131 mil en $1993^{15}$. Fuera de las 22,507 víctimas reportadas por testigos directos, $73 \%$ era activa en el mercado.

\footnotetext{
El país entero tiene alrededor de 1,900 distritos.

(VIII 184-5)

(VIII 324)
} 
En términos de las instituciones comunales, la desconfianza es un nuevo o profundizado rasgo. Las distribuciones tradicionales colectivas (ayni y minka) ${ }^{16}$ para reparar la infraestructura, cultivar la tierra y otras cosas fueron reemplazadas por un fuerte individualismo ${ }^{17}$ que afectó negativamente sobre todo a las viudas y huérfanos ${ }^{18}$. El comercio fue desbaratado y muchos comerciantes no pudieron ir al interior de sus provincias. En general, muchas de las provincias más afectadas estaban paralizadas, la guerra aceleró su decadencia y muchos pueblos progresistas perdieron su perspectiva.

\section{El silencio como una secuela del horror y la humillación}

Basándose en las más de veinte mil entrevistas, la Comisión de la Verdad y Reconciliación elaboró un análisis de las consecuencias psico-sociales del conflicto. Encontramos ahí que una de las principales secuelas es el silencio que la guerra impuso y que continúa imponiendo en muchos de aquellos directa e indirectamente afectados por la violencia en esos años.

El silencio es un hecho complejo a tal punto que puede ser considerado tanto un aspecto de la libertad, una expresión del ejercicio de la libertad como el resultado del miedo y la opresión, como un aspecto del sufrimiento. Algunas veces las fronteras entre estos silencios no están claras del todo. Los elementos sociales e individuales, externos e íntimos, interactúan de manera distinta de acuerdo al tipo de experiencia, de contexto y a las características de los agentes involucrados. El silencio incluye no decir pero también no preguntar ${ }^{19}$.

16 La reciprocidad en medio de las familias y el trabajo colectivo para la comunidad.

17 (VIII 343)

18 (VIII 344)

19 El número pequeño, donde lo hay, indica que es un testimonio y corresponde al número correspondiente en la lista de testimonios. Cuando no hay un número pequeño es porque la cita fue tomada de los autores del Informe. «La capacidad de saber 
El reporte interpreta ese silencio opresivo como una de las principales consecuencias de dos factores: el miedo y la desconfianza creados por el horror durante el conflicto. Se dirá: «el miedo y la desconfianza generaron silencio» ${ }^{20}$.

El miedo fue general. «Durante el tiempo de violencia, el miedo fue el sentimiento más generalizado. De ser una experiencia personal y subjetiva se convirtió en una realidad compartida por todos, trascendió la esfera de lo privado haciéndose experiencia colectiva y clima social» ${ }^{21}$. De acuerdo al reporte: «un factor decisivo del carácter traumático de dichas experiencias fue la imposición del silencio» ${ }^{22}$. En esta parte, recapitulamos y organizamos las clases o aspectos de silencio que el conflicto impuso.

Aunque se yuxtaponen en muchos casos y cada silencio particular puede ser visto desde la mayoría o todas las perspectivas que vamos a presentar, proponemos la siguiente clasificación para eventualmente evaluar formas prácticas de superarlo.

\section{Silencio instrumental, silencio para.}

Podemos distinguir algunos silencios que son concientemente administrados, generalmente protectores. Una de las principales razones para mantenerse callado es evitar un mayor sufrimiento individual o familiar, tiene la intención de protegerse uno mismo o a

y conocer fue especialmente blanco de ataques durante el tiempo de la violencia. Saber se hizo peligroso en varios sentidos. Quienes indagaban, averiguaban, eran objeto de sospecha, de amenaza: «nada más iba por un ratito no más, ya no quería estar ahí ya, tenía miedo yo misma, porque me decían te puede pasar cualquier cosa porque mucho estás averiguando tú, me decían»».591 (VIII 290). «El miedo cerró las bocas, clausuró la palabra, dificultó el pensar. Aún ahora es difícil pensar sobre lo sucedido» (VIII 289).

(VIII 188)

(VIII 187)

El Informe encuentra que «otros encontraron que el silencio era una forma más 
otros. Muchas expresiones de este silencio han sido presentadas ${ }^{23}$. Ha sido muy común el mantenerse en silencio cuando no se ha querido informar a aquellos que son considerados enemigos. Razones ideológicas y religiosas fortalecieron a los torturados hasta límites inimaginables ${ }^{24}$. Ésta puede ser una forma relativamente simple de silencio; tiene un propósito deliberado y generalmente es conciente. Las consecuencias de este silencio, sus costos para las personas, sus familiares y vecinos pueden ser, sin embargo, muy grandes. Asesinatos y torturas ha sido frecuentemente las causas de este tipo de silencio.

También es de este tipo general el silencio para ocultar u ocultarse, buscado a través del anonimato. Todo indica que este silencio ha sido muy común e implica una mayor o menor pérdida de identidad ${ }^{25}$. Este silencio incluye a muchos de los que tuvieron que migrar a ciudades ${ }^{26}$.

pertinente y eficaz de defensa» (VIII 282).

A propósito de la experiencia en prisión, el reporte señala que «este silenciamiento que se recoge en los testimonios, obedece tanto a complejos procesos psicológicos que han reprimido el sufrimiento y el dolor como defensa individual en busca de la restitución de un equilibrio aunque fuese precario, pero también como resultado de una formación política que se sostiene en la represión de los afectos, de las necesidades e intereses individuales, colocando por encima lo que llaman «el interés general del pueblo»» (VIII 256).

A la larga el ocultamiento o negación del nombre, o de otros aspectos de la persona, su estigmatización, constituyeron una experiencia que conllevó cuestionamientos a su identidad y a su autoestima, además de falta de reconocimiento y valoración por parte de otros (VIII 242).

También estigmatizando a las personas por su origen, por el lugar donde nacieron, por su procedencia étnica, se atentó y atenta contra su dignidad. Miles de ayacuchanos, de ashaninkas, de pobladores de barrios como Raucana, Huaycán en Lima, sufrieron, sufren desprecio y marginación. Como reacción ellos terminan por avergonzarse de esos rasgos de su identidad, por ocultarlos, causando heridas a su autoestima y a su identidad.

D: Acompáñeme, «¿tú eres ayacuchano?, sí, sí», le dije; [...] «ayacuchano, ¿qué haces acá, qué haces andando?», «estoy yendo a buscar trabajo», le dije; [...] entonces ahí en la PIP ya llegamos, ya nos pusieron un cuartito [...].

Me dicen «tonto, por qué dices que eres ayacuchano», me dicen; yo por qué voy a mentir ¿no?, [...] «por qué has dicho, ahora te van a pegar», me dice. [...] yo también hubiera dicho otro sitio yo soy de acá de esta zona, de repente me hubiera soltado 
Los silencios más individualmente traumáticos tienden a ser, entre otros, aquellos que tienen por objetivo y son causados por la necesidad de no ser culpados por lo que ciertas personas individualmente o la familia piensa que uno pudo hacer pero no hizo. Sentimientos de culpa llevan al silencio ${ }^{27}$. El silencio para evitar la vergüenza está también muy difundido ${ }^{28}$.

Otra causa común y objetivo del silencio es la intención de no ser estigmatizado por la familia y la sociedad. Esto ha pasado más frecuentemente con mujeres que sufrieron de violación sexual ${ }^{29}$, viudas $^{30}$ y huérfanos que son vistos como símbolos de algo que se trata de olvidar. Dentro de los estigmatizados se incluye a muchos de los que viven en alguna región en donde la violencia fue mayor o donde la mayoría de las victimas vivió o vive.

En Perú esa región es principalmente Ayacucho ${ }^{31}$. Una comunidad campesina famosa por matar a seis periodistas (Uchuraccay) tuvo que ocultar la identidad de sus muertos; ésa era una manera de asegurar su propio anonimato y su ya restringida libertad. También el anonimato de los miembros de familia o amigos que sobrevivieron ${ }^{32}$.

comencé a pensar, pero ya he dicho ya ¿no? 467 (VIII 250).

27 «Si mi hijo no hubiera venido, porque nosotros vivíamos en Vinchos, ahí estaba estudiando mi hijo [...] Ahí al frente estudiaba y mi esposo le dijo: «Tienes que ayudarme los sábados y domingos a arar la chacra» «428 (VIII 238).

«El mandato externo de callar se conjugó con la prohibición interna de hablar, impuesta por el miedo. A muchas personas les resultó difícil hablar del miedo que experimentaron y al hacerlo nos hablaron de haberse sentido o sentirse aún avergonzados, quizá porque el miedo confronta con sentimientos de impotencia y desvalimiento, porque se asocia a la idea de falta de valentía en la que muchos son socializados, pero sobre todo porque el sentimiento de vergüenza expresa con claridad la humillación de la que han sido objeto» (VIII 199).

(VIII 244, 245, 250, 258)

(VIII 209)

(VIII 229)

«En ese sentido, para los uchuraccaínos, la matanza de los periodistas significó la barbarie de la represión y su propia negación: morir asesinados bajo las múltiples incursiones, perseguidos y desterrados en el exilio, y vivir en el silencio del anonimato. Eso los llevó también, por supuesto, a vivir silenciando a sus propios muertos» (VIII 230). 
Algunos declararon que preferían mantenerse en silencio para ocultar su propio resentimiento ${ }^{33}$ y el deseo oculto de más violencia doméstica o social ${ }^{34}$.

Éstos diríamos que son principalmente casos de silencios defensivos, socialmente protectores, con un propósito, silencio instrumental podríamos decir.

\section{2. ¿Qué es silenciado? Silencio de.}

Las cosas o hechos que se mantienen en silencio son algunas veces suficientemente claros. Es el caso de alguna información sobre lo que en verdad pasó en determinadas circunstancias ${ }^{35}$. El ocultamiento de información sobre la propia identidad o cultura puede ser particularmente dañino en algunas circunstancias, por ejemplo, cuando uno es conciente de tal acción. La identidad puede tomar la forma de ideas políticas ${ }^{36}$ o de creencias religiosas. La reacción al sufrimiento, temor y humillación ha sido una fuente principal de silencios y de uno más complejo y traumático. Silencio después de haber asesinado a sus propios hijos ha sido recientemente reportado ${ }^{37}$. Silencio de las humillaciones y pérdida de dignidad sufridas ha sido muy extendido. El maltrato psicológico,

(VIII 267, 274)

«Algunos testimonios nos muestran el carácter devastador del miedo cuando suscita en las personas la necesidad de recurrir a los mecanismos de defensa menos organizados, al ataque impulsivo hacia otros o hacia sí mismos, como por ejemplo a actos de venganza ciega que convierten a la víctima en victimario. Mucho del clamor de muerte para enfrentar a la muerte, responde al miedo» (VIII 196).

(VIII 290)

(VIII 250, 258)

[...] la propia madre mató a su hijo [...]. Era de noche y no sé a dónde lo habrán llevado, tampoco sé si lo han enterrado. Era un bebito, habrá tenido aproximadamente medio año... lloraba mucho y para que no lo oyeran los soldados llamaron a la madre y le dijeron ¡miserable, calla a tu hijo! y cuando le obligó a callarlo, ella [la madre] lo apretó entre sus senos al bebé y éste murió asfixiado, le quitó la respiración [...] 367 (VIII 214).

(VIII 250) 
desnudamiento, insultos al ser torturados o sexualmente violados son importantes en sí mismos ${ }^{38}$. La cultura y la identidad han sido $\mathrm{y}$ aun son en muchos casos los motivos para insultar o degradar. La relación entre ser «indio» y ser tratado peor que animales fue permanentemente reportada. La mayoría entre los soldados y policías difícilmente se diferenciaban racialmente de aquellos que maltrataron.

Las mujeres fueron afectadas de forma especial. Sin embargo, muchas de ellas murieron en matanzas masivas, ejecutadas o asesinadas pero también muchas fueron arrestadas, torturadas, secuestradas, desaparecidas y muchas también sexualmente violadas ${ }^{39}$. Las fuerzas armadas fueron las culpables de la mayoría de las violaciones ${ }^{40}$. Algunas mujeres con hijos tuvieron que «probar» a sus vecinos que fueron ultrajadas ${ }^{41}$. Todo esto ha sido una importante fuente de silencio. «Si hay un tema capaz de producir la mudez es la violación» dice uno de los investigadores del proceso ${ }^{42}$.

También incluimos acá el clamoroso silencio individual y colectivo, el silencio social que se dio durante la guerra y que es un asunto político y moral clave en el informe porque expresa la enorme distancia social y emocional entre grupos sociales en el Perú y particularmente la presencia prevaleciente de discriminación étnica. Los medios de comunicación han sido particularmente responsables por este tipo de silencio.

\footnotetext{
39 (VIII 79)

$40 \quad$ (VIII 244)

41 «Me sentí suicidar, me sentí deshacerme todo, matarme, porque tenía una vergüenza grande. Yo pensé que la gente me criticaba porque [...] habrán pensado que [...] yo me andaba como quiera con el hombre o me embaracé de buena voluntad [...]. Y ahora me dicen mi suegra [...] «debes ir a buscar a su padre, vivirá pues su padre $[\ldots]$ ¿quién te va creer que tú has sido violada? [...]. Una sola vez no más que te ha violado gente, como vas a tener hijo» me dijo». 453 (VIII 245)

42 (VIII 244) Hay recopilaciones, ensayos y reflexiones acerca de cómo sufrió la mujer durante esos años. Vea, por ejemplo: Varias (2002) y Varios (2003).

43 (VIII 290)
} 
3. Silencio ¿con quiénes? Silencio con.

El guardar silencio con el enemigo, con el torturador, para esconder información fue algo normal al menos hasta cierto punto $^{43}$. Éste era el último refugio de dignidad. En muchos casos este silencio no implica ausencia de palabras, muchos tuvieron que declarar y firmar lo que el interrogador les dijera.

Algunos silencios son más dolorosos que otros dependiendo del tipo de «otro» (padre, hijo, etc.) que se ha perdido o es afectado por dicho silencio. En muchos casos ha sido y es aun común el silencio por la ausencia de padres, hermanos y hermanas en quien confiar, mayormente porque están muertos. Sueños y visiones son comúnmente reportados. Silencio con los propios hijos y con la familia es particularmente dañino y muy difundido y, todavía después de muchos años, una realidad. El silencio de los ancianos y ancianas que sobrevivieron y han permanecido solos en sus casas en comunidades campesinas también ha sido reportado ${ }^{44}$.

La dimensión temporal es importante en este sentido. Muchas veces las personas tienen que tomarse un tiempo para buscar al interlocutor correcto para contarle lo sucedido y luego buscar el momento adecuado para hacerlo. En cualquier caso no es fácil informar acerca de desapariciones de parientes cercanos o en prisión y más difícil aun explicar qué es lo que sucedió y por qué. Uno puede pensar que aquellos que podrían ayudar muy probablemente podrían no comprender, no estar en capacidad de procesar la información y debido a ello no estar en disposición de ayudar.

También es común el silencio con las esposas y amigos de aquellos que torturaron y asesinaron o que denunciaron. 
La falta de cohesión social a niveles locales es otro factor que se presenta usualmente. La fragmentación social ha sido generalizada $^{45}$. La falta de confianza es muy común en las localidades que han sobrevivido a la guerra, y donde unos estuvieron en un bando y otros en el opuesto o algunos en ambos dependiendo de las circunstancias ${ }^{46}$. Muchas veces esa distancia psicológica y social impide el regreso de las formas colectivas de trabajo ${ }^{47}$.

Un tipo muy común de silencio es el que ocurre cuando muchos han desaparecido y han sido asesinados, es con los propios muertos. La gente quiere «comunicarse» con ellos ofreciéndoles un funeral decente. Un tipo de silencio que ha surgido muy usualmente es el que aparece debido a la falta del debido luto cuando son contados entre los desaparecidos y más aun cuando ni siquiera están entre los que se cuentan como tales o cuando han sido considerados correcta o incorrectamente terroristas o simplemente entre los derrotados ${ }^{48}$.

\section{Los silencios más profundos... Silencios....}

Aun muchos están íntimamente atemorizados. Algunas de las experiencias más difíciles han creado los tipos más traumáticos de silencios y han dado lugar a formas más profundas de silencio. Están instaladas en las profundidades del ser y tales silencios son en sí mismos dañinos. Por ejemplo, silencios por la falta de memoria sobre lo sucedido ${ }^{49}$. El mantenerse en silencio debido a la falta de energía o vitalidad ha sido también reportado ${ }^{50}$. También el silencio por la falta de una mínima paz mental, por la ansiedad y tristeza que llenan los días. El silencio interior es mencionado

(VIII 219, 288, 256)

(VIII 212)

(VIII 199)

Ellos estaban «privados también de quien pudiera garantizarles una buena muerte, atendida» (VIII 212).

(VIII 278)

(VIII 278-9) 
como un vacío ${ }^{51}$ (un sentimiento de haber perdido algo). Más intelectualmente, encontramos silencio por la dificultad para entender el sufrimiento ocasionado o por haber presenciado asesinatos y torturas ${ }^{52}$, sobretodo de seres queridos. La falta de comprensión y la dificultad para poder darle un sentido a lo sucedido lleva a un profundo silencio ${ }^{53}$.

También se presenta el silencio individual debido al desinterés social ${ }^{54}$, al lugar social estigmatizado y muchas veces internalizado particularmente por las mujeres que sufrieron violación sexual y por los viudos o por los oriundos de regiones especificas $^{55}$. Paisajes sociales e íntimos interactúan para producir tales silencios. Algunos se refieren a situaciones donde hubieron demasiados pensamientos y otros a la «falta de pensamiento» ${ }^{56}$ (falta de capacidad de razonar). Ambos pueden coexistir.

Cuando el daño sufrido es muy profundo no puede ser expresado $^{57}$. No hay palabras ni símbolos que puedan hacer eso. Señales contradictorias impiden la expresión del sufrimiento ${ }^{58}$. «La gran mayoría de las personas que han sufrido por la violencia ha estado expuesta todo este tiempo a mensajes contradictorios, im-

«Al no encontrar explicaciones a su sufrimiento crean algunas buscando consuelo, pero sobre todo protección contra el vacío del silencio» (VIII 289).

52 (VIII 204, 218)

53 «Uno de los elementos que hace traumática a una experiencia como la vivida es la ausencia de sentido» (VIII 288).

54 Ese punto es permanentemente enfatizado por el presidente y otros miembros de la Comisión. Hubo, sin embargo, algunas reacciones (I 40, 44; II 314, 361, 421; IV 286).

$55 \quad$ (VIII 299)

56 «...vivieron como estados de locura, pues sienten que en esos momentos no se reconocían a sí mismos, estaban extraños, fuera de sí. Otra expresión frecuente es mucho pensamiento para dar cuenta de lo invadida que queda la mente de una persona por la tristeza, la pena, la preocupación. Con la expresión sin pensamiento aluden a la ausencia de capacidad para pensar en nada. La persona se siente como $i d a$, trastornada» 553 (VIII 277).

$57 \quad$ (VIII 261, 269)

58 (VIII 288-9) 
posibles de ser procesados sin cuestionar el equilibrio psicológico. La negación de muchos hechos por parte de las autoridades, el desconocimiento de sus responsabilidad, el ocultamiento de los culpables, la impunidad que pretendió callar y olvidar todo como si no hubiera ocurrido, el desinterés y desconocimiento de lo que vivieron y viven hasta hoy, por parte del resto de la población, entra en contradicción desconcertante con la certeza y contundencia de sus heridas, con la intensidad de su llanto, de su indignación. A miles de personas, la sociedad, las instituciones, el estado les ha negado la primera palabra de consuelo que es el reconocimiento de su dolor, de sus pérdidas» ${ }^{59}$.

\section{Conclusiones}

La violencia crea silencio de muchas formas diferentes. Cualquier guerra produce diferentes tipos de silencio aún sin proponérselo. Pero el silencio que hemos presentado ha sido también un silencio cultivado por todas las partes activas del conflicto. Sendero Luminoso era especialmente cuidadoso en el fortalecimiento de su poder sobre las mentes de sus víctimas. Muchas veces la tortura incluía destrozar cerebros frente a todos, cortar lenguas, destruir los ojos y cortar las orejas ${ }^{60}$. En muchas ocasiones ésta era la forma en que Sendero Luminoso asesinó a aquellos

(VIII 288-9)

«En esos instantes salieron los dos senderistas de la choza y mi padre saludó «buenos días jefe». Uno de ellos se dirigió a mi padre y el otro se quedó y no nos dejó salir, amenazándonos con el arma y nosotros por temor tuvimos que obedecer y no sabíamos qué hacer, sólo escuchábamos los quejidos de mi padre por los golpes que le daban y en eso oímos que mi padre suplicaba «por favor ya no me maltraten mejor quítenme la vida». A mi parecer, le dio una patada en el estómago y cuando mi padre se estaba desmayando lo apuñalaron con un cuchillo hasta traspasarlo lo cual el cráneo y el cuerpo estaba unido tan sólo por una piel delgada [...] Después de haberlo ejecutado nos dejaron salir de la choza, luego se lo llevaron al batan y pusieron la cabeza de mi padre y cogieron una piedra del corral con el cual procedieron a triturar la cabeza» 337 (VIII 205). 
que eran considerados capaces de informar a las fuerzas armadas $^{61}$. No sólo Sendero Luminoso utilizó este tipo de tortura y asesinato, también las comunidades campesinas organizadas en «rondas» con el respaldo de las fuerzas armadas ${ }^{62}$. Niños pequeños no escaparon a este destino ${ }^{63}$. Animales y torturadores compartieron tal práctica ${ }^{64}$. Destruir la capacidad de pensar es el objetivo de todo tipo de terroristas y también el resultado del temor y el pánico ${ }^{65}$. Se decía que los «ojos y oídos» de Sendero Luminoso estaban en todas partes ${ }^{66}$, en las rocas, en el aire, en

«Miembros del PCP-SL también utilizaron el maltrato físico y emocional como castigo y amedrentamiento. «Me amenazaron con matarme, pero sí, me dieron golpes, a puntapiés, como cualquier cosas, como animal pues. Después me decían de que nunca más hable en contra del partido». 461 «A mi amigo le habían dado un balazo, le rociaron gasolina y le prendieron fuego, otro colega sin ojos, sin lengua, sin uñas»» 462 (VIII 248).

No sólo los senderistas hacían eso. También los campesinos organizados en rondas con la protección de las fuerzas armadas. Por ejemplo un testigo declara: «le teníamos más miedo a los ronderos y a los militares, especialmente a los ronderos porque mataban así nomás [...] sus ojos de la mujeres sacaban, sus senos los cortaban, sus dedos les sacaban, sus orejas cortaban, entonces de eso tenía miedo. Así aniquilaban [...]» 402 (VIII 227). «A mi hijito le ha roto la cabeza, chancado hasta adentro, era como huevo, llorando, así agarrando a mi bebé nos hemos ido para atrás del cerro a vivir, ahí hemos vivido todos los [...] todo lo que tenía en la casa se han llevado» 474 (VIII 253).

«Mi marido al encontrar tuve llevar a enterrar, que ya estaba hasta comido por el perro, sin sangre, ni lengua tenía [...] sin lengua, sin nariz, sin ojos, sus cabellos y sus ropas estaban podridos, bien blanqueado estaba su carne, sin piel, sus cabellos estaban a un lado podrido y los tuve que hacer juntar para enterrarlos» 411 (VIII 232). «Una de las funciones más afectadas al experimentar terror, es la capacidad de pensar, de reflexionar, de hacerse un juicio sobre lo que está aconteciendo y poder planear una acción. Resulta tremendamente significativo, cargado de simbolismo, el hecho de que muchas personas relatan cómo las cabezas, los cráneos y las lenguas de las personas asesinadas fueron objeto de ensañamiento, de destrucción. Con ello, los agresores muestran su afán de callar a las personas, de dejarlas sin el recurso expresivo y orientador de la palabra, así como de destruir su mente, su capacidad de pensar» (VIII 194).

66 A propósito del ejercicio de gobierno local el relato dice que «las autoridades apenas podían ejercer sus roles. Las normas que regían la organización habían sido secuestradas por la organización subversiva que llegaba a controlar la zona y ejercía el poder. La frase de «los mil ojos y mil oídos» degeneró la vida social pública y convirtió la sociedad en una especie de panóptico global, es decir, un lugar donde todos se sentían vigilados, trastocando el sentido de la libertad entre los pobladores. 
la naturaleza ${ }^{67}$. Como alguien declaró refiriéndose a Sendero Luminoso: «ellos tenían su ley máxima, eran tres cosas, ser ciego, ser mudo y ser cojo» ${ }^{68}$.

Creemos que las aproximaciones al silencio resultante de una guerra interna en Perú que hemos propuesto pueden ser usadas para establecer diferentes formas de atacar el problema. El silencio protector y con un propósito puede ser reducido, eliminando muchas de las razones que fortalecen tales propósitos. Eliminar o reducir las razones para estar temerosos por la seguridad propia o de otros es evidentemente un camino. Además, la efectividad de los derechos individuales reducirá la necesidad de mentir o de ocultar. Simplemente con registrar a los recién nacidos en las comunidades o distritos y provincias alejados de las vías de comunicación será un paso enorme hacia el reconocimiento social y el respeto. Los hechos que fueron «silenciados» no deberán ocurrir nuevamente.

El silencio que resulta de la fragmentación de la familia puede ser confrontado con políticas orientadas a su reunificación. Encontrar las tumbas o fosas comunes esparcidas alrededor de las comunidades campesinas es también extremadamente importante.

El silencio más profundo tiene un obvio contenido psicológico que en muchos casos requiere tratamiento directo, personalizado. A la vez, el reconocimiento del sufrimiento tiene que ser expresado económica, política y socialmente para reducir el daño hecho. El aspecto social del problema, revertir el silencio social, puede ayudar en algunos casos a su aspecto individual.

De la noche a la mañana la vida cotidiana se convirtió en un ámbito cerrado bajo vigilancia permanente, y donde la desconfianza era el clima social natural para la supervivencia» (VIII 317).

(VIII 317)

(VIII 313) 
La tarea no es fácil. El Informe de la Comisión de la Verdad y Reconciliación está siendo ignorado por la mayoría de las elites económicas y sociales del país. Los principales partidos políticos, con distintos matices, también lo están ignorando. La tradición secular de indiferencia y olvido hacia la gente indígena que vive en las alturas y en el espesor de la Amazonía está volviendo después de pocos meses cuando la CVR estaba difundiendo a través de audiencias públicas las experiencias de los afectados en los medios de comunicación. El pobre, el «inexistente» ${ }^{69}$ se está volviendo, otra vez, invisible. Es como si la guerra no hubiera enseñado nada a la mayor parte de las elites peruanas, las cuales sintieron que la guerra no era un asunto que les concerniera ${ }^{70}$. La gran división en la sociedad peruana, la distancia entre diferentes culturas, razas y regiones aun existe y con ésta, la falta de libertad de expresión, uno de cuyos aspectos más terribles es el silencio.

\section{Referencias}

Comisión de la Verdad y Reconciliación, Perú. (2003). Informe final. Lima: CVR.

Iguíñiz, J. M. (2001). Desarrollo como liberación y libertad: introducción a Sen y Gutiérrez. Páginas, 163, 19-31.

Iguíñiz, J. M. (2003). Desarrollo, libertad y liberación. En Amartya Sen y Gustavo Gutiérrez. Lima: Fondo Editorial de la PUCP-CEP-IBC.

Macher, S. (2004, 23 de agosto). Cara y sello de la CVR. El Comercio, p. A5.

La «no existencia» y su significado para la sociedad inspiró un importante trabajo teológico en América Latina. La relación entre el «desarrollo como libertad» en el Enfoque de Capacidades sobre el desarrollo y el «desarrollo como liberación» en tal teología está analizada en Iguíñiz (2001) y en mi libro (2003). Ésa es la conclusión de Macher (2004). 
Silencio como secuela de la guerra interna en Perú

Tovar, C. \& Bazán, M. (2004). Huellas de la violencia política y respuestas de la población. Lima: Instituto Bartolomé de las Casas.

Varias. (2002, marzo). Rompiendo el silencio. Las voces de las mujeres en la búsqueda de la verdad. Foro público Rompiendo el silencio. Lima: Comisión de la Verdad y ReconciliaciónUSAID.

Varios. (2003). Abusaruwanku. Violación de mujeres: silencio e impunidad. Lima: COMISEDH-Manuela Ramos. 